\title{
Implementation of the Meningitis Vaccine Project in Africa: lessons for vaccine implementation programs
}

\author{
Obidimma Ezezika1, Meron Mengistu², Thomas Lear ${ }^{3}$ \\ 1 Department of Health and Society, University of Toronto Scarborough; Dalla Lana School of Public Health, University of Toronto; African Centre for \\ Innovation \& Leadership Development, ${ }^{2}$ Department of Health and Society, University of Toronto Scarborough; London School of Hygiene \& Tropical \\ Medicine, ${ }^{3}$ Department of Health and Society, University of Toronto Scarborough \\ Keywords: meningitis, implementation, vaccine, immunization \\ https://doi.org/10.29392/001c.29042
}

Journal of Global Health Reports

Vol. 5, 2021

\begin{abstract}
Background
The Meningitis Vaccine Project (MVP) was an international partnership that began in 2010 and focused on the development, testing, licensure, and widespread introduction of a conjugate vaccine with the promise of protecting millions of lives from group A meningococcal meningitis. To bridge gaps upstream of vaccine administration and in understanding the project's planning, delivery and outcomes, the primary objective of this study was to delineate the barriers to and facilitators of sustainable implementation in an upstream context of the delivery of the MenAfriVac vaccine and to draw critical lessons for other vaccination programs.
\end{abstract}

\section{Methods}

We conducted a qualitative study with key project partners and leaders who worked on the MVP project. The interviewees were initially identified through a literature review and a search of publications and evaluations of the project. Eighteen key stakeholders were interviewed. The interviewees included individuals in the roles of implementation oversight, champion, partner, funder, and frontline implementer. The Consolidated Framework for Implementation Research (CFIR) informed the identification of a priori codes for the directed content analysis.

\section{Results}

There were multiple barriers and facilitators to implementing the vaccine under all five domains of the CFIR framework, including intervention characteristics, outer setting, inner setting, characteristics of individuals, and process. The most common domains mentioned by stakeholders that facilitated the success of the MVP were inner setting and process; specifically, three constructs were most representative-Tension for Change, Formally Appointed Implementation Leaders, and External Change Agents.

\section{Conclusions}

The tension for change-that is, the degree to which stakeholders perceive the current situation as intolerable or needing change- advocated by African leaders served as a crucial foundation for solid leadership for the MPV. The leadership came in the form of the project director and other formally appointed leaders, who could plan, engage and execute the project's goals effectively. This leadership translated into consistent messaging, information sharing, and multiple levels of engagement with external change agents (including technical experts), which promoted a shared sense of readiness contributing to significant change investments in implementing MVP.

Meningococcal meningitis is found in many populations worldwide, and its subtypes are typically confined to specific geographical regions. Neisseria meningitidis serogroup A (hereafter referred to as meningitis A) accounted for $90 \%$ of meningitis cases in sub-Saharan Africa. ${ }^{1}$ Meningitis A causes infection of the central nervous system, in the lining of the brain and spinal cord, and its transmission is fa- cilitated through respiratory droplets or throat secretions. Despite rapid diagnosis and treatment, there remains a $5 \%-10 \%$ fatality rate, typically within $24-48$ hours of the onset of symptoms. ${ }^{2}$ The urgency for a more effective vaccine was evident after the 1996 outbreak of meningitis A in the meningitis belt, which spans from Senegal to Ethiopia, infecting over 250000 people and killing 25000 within a few 
months. ${ }^{3}$ Several African leaders called on the World Health Organization (WHO) to resolve the meningitis epidemic. In 2001, the Bill and Melinda Gates Foundation (BMGF) officially funded the Meningitis Vaccine Project (MVP) with a partnership between the WHO and the Program for Appropriate Technology in Health (PATH). By 2003, after almost a year-long delay in identifying a suitable pharmaceutical partner to produce the vaccine at the requisite cost, the Serum Institute of India agreed to produce the meningitis A vaccine, called MenAfriVac, at US $\$ 0.50$ a dose. ${ }^{4}$ In response to this catastrophic outbreak, the BMGF awarded US\$70 million to the WHO and the PATH to establish the MVP.

Ever since, MenAfriVac has witnessed widespread adoption to over 300 million Africans across 22 of 26 target countries in the meningitis belt, including Burkina Faso, Niger, Mali, and surrounding areas. 5,6 Collaborative efforts in establishing the MVP led to a large-scale vaccine campaign in December 2010 in Burkina Faso, Mali, and Niger. ${ }^{7}$ One of the greatest success stories can be found in Burkina Faso, which suffered a major epidemic of meningitis A with 45000 cases between 2006 and 2008. Since the introduction of MenAfriVac, there have been only eight cases in Burkina Faso between 2011 and 2017. ${ }^{1}$ Burkina Faso is one of the few countries that has conducted a catch-up campaign among children and infants to accelerate the timeline for the introduction of MenAfriVac into the Expanded Program on Immunization (EPI). However, gaps continue to persist, with unvaccinated cohorts increasing due to a lack of integration of routine national immunisation programs and catch-up campaigns. $^{4}$

The MVP is a valuable initiative to study, with crucial lessons to be drawn from it for future implementation projects and initiatives. This study aims to identify the barriers to and facilitators of the implementation of MenAfriVac through the MVP. Despite the intervention's effectiveness, a host of social determinants or upstream contextual gaps decreased diffusion. ${ }^{8,9}$ As is becoming evident through growing implementation literature, it is not sufficient to know that an intervention is effective but rather what contexts it works best in and how. ${ }^{10}$ In Burkina Faso, there are vaccination coverage gaps among regions, thereby prompting further inquiry regarding attaining sustainable implementation. ${ }^{5}$ To this end, we aim to identify the contexts of MenAfriVac at the level of multilateral organisations, governments, decision-makers, and academics that lead to challenges or successes in implementing the vaccine.

In this regard, several implementation science studies are of significance as they attempt to fill a specific research gap through the analysis of primary data. The implementation science studies relevant to MenAfriVac have highlighted the numerous downstream consequences of implementation, such as demonstrating the potential socio-cultural, economic, and environmental factors that enhance the seasonal transmission of meningitis A. ${ }^{11}$ Moreover, a 2019 study analysed routine coverage of MenAfriVac and the continued socio-economic obstacles to achieving high coverage of both MenAfriVac and the measles-containing-vaccine second dose (MCV2). ${ }^{12}$ Furthermore, several studies have examined the MVP, but none have done so from an upstream perspective. Two recent qualitative studies on the MVP do well at examining downstream perspectives of the MVP, including the viewpoints of health care workers ${ }^{13}$ and individual perceptions of recurrent meningococcal epidemics in Ghana. ${ }^{14}$ Therefore, questions on upstream delivery-such as how stakeholders and partners interacted, how information was shared, what kinds of decisions were made between different organisations and institutions, and how these decisions were implemented-were left unanswered.

To this end, we employed a conceptual framework known as the Consolidated Framework For Implementation Research (CFIR), which has been developed to guide the systematic assessment of implementation contexts and factors that influence effective intervention implementation. ${ }^{15}$ Incorporating CFIR during the analysis and synthesis phase of this review is beneficial, as integrating a conceptual framework increases the generalizability and interpretability of study results. To further explain the results of this study, we used the organisational readiness for change (ORC) theory, a multifaceted construct that describes change commitment and change efficacy. ${ }^{9}$ The theory effectively characterises organisational views on implementation and may be used to advise the changes required to yield the desired outcomes. A recent study utilised the ORC theory to understand the association between readiness for change and psychosocial conditions of health care professionals (HCP). ${ }^{16}$

Our aim was to address the following research question: "Which are the upstream facilitators of and barriers to the effective implementation of MenAfriVac? The findings of this study may inform generalisable quality improvement strategies for vaccinations in SSA, create a better qualitative understanding of the needs and resources of stakeholders, and promote the complete eradication of meningitis by highlighting directions for advocacy.

\section{METHODS}

\section{STUDY PURPOSE AND SAMPLING STRATEGY}

This study aimed to identify the barriers to and facilitators of implementing MenAfriVac through the MVP. The leaders and partners of the MVP were initially identified through a literature review of publications related to the project and were interviewed as key informants.

Potential stakeholders for this study included those involved in the upstream processes of the project, including planning, decision-making, and implementation. Eligibility included direct involvement - either individually or through an organisation/affiliation - in the MVP initiative. Key informants also needed to have experience of the project's initiative in the context of the Meningitis Belt countries.

Eighty-nine individuals were identified as potential stakeholders and were contacted for an interview. Two-way communication was established among forty-seven of the potential stakeholders, and out of them, twenty-six stakeholders did not meet the eligibility criteria and therefore could not be interviewed.

Of the remaining twenty-one eligible stakeholders who responded, three declined due to schedule constraints. Ul- 
timately, 18 stakeholders agreed to participate in this study and were interviewed.

\section{PARTICIPANTS}

Stakeholders who participated in the interviews played various roles that contributed to the MVP initiative. These roles included technical, regulatory governance, capacity building, deployment, communication, and charitable contributions. Participants responsible for the technical and regulatory processes of MenAfriVac contributed to full-scale manufacturing, exploratory and pre-clinical research, vaccine trials and surveillance, and post-licensure stages. Moreover, participants in governance roles were responsible for overseeing these various stages of the value chain to provide support, resources, and consultation. The distribution and delivery of MenAfriVac was the responsibility of the participants in the deployment role, and participants responsible for communication led various sensitisation campaigns. Lastly, some participants were affiliated with charitable organisations that led the finance aspect of the project and funded the manufacturing stage.

\section{DATA COLLECTION}

OE \& MM met on two separate occasions to review the interview questions and run through a mock interview. This was done to ensure that MM was trained and that interview etiquette was established. Interviews were conducted by MM between July 14, 2020, and October 14, 2020, on Zoom. Interviews lasted for approximately 20-80 minutes. A semistructured questionnaire was employed, and interviews were recorded to be subsequently transcribed and analysed. During the interview, each stakeholder was asked to describe their role and responsibility in the project, including critical barriers to and facilitators of distributing MenAfriVac that they came across in their capacity. Furthermore, stakeholders were asked to identify any processes that could have been strengthened to denote the significant lessons learned from implementing the project. All 18 interviews were transcribed manually using the audio files saved and prepared as a Word document for data analysis.

\section{DATA ANALYSIS}

The transcripts were analysed using NVivo, a qualitative research analysis tool. ${ }^{17}$ The 18 interview transcripts were individually assessed by MM and TL to identify the barriers and facilitators mentioned. For this stage, MM and TL met four times: once to go over the first three barriers and facilitators to establish coding criteria, the second time to reach a consensus regarding all the facilitators of and barriers to each interview; and finally, twice to condense all facilitators to and barriers of from all interviews into one table. During each meeting, MM and TL shared their results and created a new table with the consensus and the interreliability score. The inter-reliability score for the barriers and facilitators after identification was $80 \%$ and $85 \%$, respectively. Disagreements in data extraction were resolved through discussion facilitated by OE. In addition, MM and OE had four meetings to validate the inter-reliability scores and further breakdown and reorganise the barriers and facilitators. In these meetings, the names given to the barriers and facilitators were revised, a few were combined, and quotations were moved around and condensed for accuracy (Table 1). This process was an extensive one.

\section{CFIR CODING}

After consensus was reached, MM and TL coded the barriers and facilitators using the CFIR (see Table 2). The CFIR is a conceptual framework developed to guide the systematic assessment of implementation contexts and factors that influence the implementation of effective intervention. ${ }^{18}$ Incorporating CFIR during the analysis and synthesis phase is beneficial, as integrating a conceptual framework increases the generalizability and interpretability of the study results. In addition, in systematic research, this framework is known to support the implementation of health care delivery interventions to produce an actionable evaluation for the improvement of implementation. ${ }^{18}$ The CFIR includes five major domains (intervention characteristics, outer setting, internal setting, characteristics of individuals, and process) with 39 underlying constructs and sub-constructs that can potentially influence efforts to change the practice. ${ }^{15}$ To reach a consensus, MM and TL met twice: the first time to go over three barriers and facilitators as a pilot to establish coding criteria and the second time to reach a consensus for all barriers and facilitators and calculate the inter-reliability score.

Further, MM and OE had two meetings to establish coding criteria, test the criteria using pilot examples, and reach a consensus by collapsing similar codes under more accurate categories and reorganising the CFIR results. These two meetings followed the same exhaustive process as the first analysis to ensure validity and consistency. Moreover, we reached out to participants with a summary of the results and received feedback, which was done to improve the validity of the data analyses process.

\section{RESULTS}

\section{INTERVENTION CHARACTERISTICS}

This domain describes the critical attributes of the intervention-in this case, the vaccine MenAfriVac-and its influence on implementation success.

MenAfriVac itself was discussed as a critical facilitator in the effective reach of populations within the meningitis belt. According to four key informants, this was facilitated by the adaptability of the vaccine through the FDA-approved technology transfer to the Serum Institute of India, the trialability through the acceptance of clinical trials in a few African countries, and the design of the MenAfriVac that led to the development of a cold-chain independent vaccine. As highlighted by one of the interviewees, "this vaccine is capable of sustaining four hours at room temperature. So, it doesn't need the cold chain infrastructure." (Interviewee 7).

MenAfriVac and its associated MVP initiative encountered a few barriers that hindered or slowed its implementation success. According to one stakeholder, an obstacle to implementation was region-wide contention on external vaccine inspections and regulations. In addition, the design 
Table 1. Barriers and facilitators with sample excerpts and their respective Consolidated Framework for Implementation Research (CFIR) constructs

\begin{tabular}{|c|c|}
\hline \multicolumn{2}{|c|}{ CFIR Domain and Construct: Intervention Source (Intervention Characteristics) } \\
\hline Barriers & Facilitators \\
\hline $\begin{array}{l}\text { Region-wide contention on external vaccine inspections and } \\
\text { regulations (1) } \\
\text { "[...] trying to get [trials] done for the first time was a challenge, it wasn't } \\
\text { easy at all. Getting countries to agree that they could do something } \\
\text { together, both ethics committees and national regulatory authorities. So } \\
\text { there, again, because it was the first time that was quite a challenge" } \\
\text { (Int \#13) }\end{array}$ & \\
\hline \multicolumn{2}{|c|}{ CFIR Domain and Construct: Adaptability (Intervention Characteristics) } \\
\hline \multirow[t]{2}{*}{ Barriers } & Facilitators \\
\hline & $\begin{array}{l}\text { FDA-approved technology transfer for the vaccine to } \\
\text { Serum Institute of India (1) } \\
\text { "So, the technology was actually made available from the FDA. A } \\
\text { group working extensively with the FDA had developed a } \\
\text { technology for conjugation of the protein to the polysaccharide, } \\
\text { which is the foundation for the vaccine, and that technology was } \\
\text { made available to Marc and his crew, put together for the } \\
\text { creation of this vaccine, at no cost" (Int \#10) }\end{array}$ \\
\hline \multicolumn{2}{|c|}{ CFIR Domain and Construct: Trialability (Intervention Characteristics) } \\
\hline \multirow[t]{2}{*}{ Barriers } & Facilitators \\
\hline & $\begin{array}{l}\text { Acceptance of clinical trials in a few African countries (2) } \\
\text { "I would say colleagues at WHO, the partnership with WHO, } \\
\text { was a great facilitator for the clinical trials, for the acceptance of } \\
\text { the clinical trials in Africa. [...] we have to say that facilitators } \\
\text { were also many African doctors who really helped trusted us and } \\
\text { really made us a lot of credit, they had credit" (Int \#18) }\end{array}$ \\
\hline \multicolumn{2}{|c|}{ CFIR Domain and Construct: Complexity (Intervention Characteristics) } \\
\hline Barriers & Facilitators \\
\hline \multicolumn{2}{|l|}{$\begin{array}{l}\text { Complexities and delays in production of vaccines (2) } \\
\text { "So only one manufacturer, one manufacturer is producing the vaccine. } \\
\text { We had the challenge, at the beginning was that we don't have enough } \\
\text { vaccine to cover all the } 26 \text { countries." (Int \#17) }\end{array}$} \\
\hline \multicolumn{2}{|l|}{$\begin{array}{l}\text { Complexities and delays in vaccine development (2) } \\
\text { "[...] Some of the challenges were with the actual vaccine development. } \\
\text { [...] the challenge with, you know, starting off with one kind of } \\
\text { technology and they left the project and we had to find another one." } \\
\text { (Int \#11) }\end{array}$} \\
\hline \multicolumn{2}{|c|}{ CFIR Domain and Construct: Design Quality and Packaging (Intervention Characteristics) } \\
\hline Barriers & Facilitators \\
\hline $\begin{array}{l}\text { Narrow-scope vaccine immunity (Single serogroup) (2) } \\
\text { "Yes, the other challenge also is that the vaccine protects against one } \\
\text { serogroup, the meningococcal Meningitis A. So doesn't protect against } \\
B, C, X, Y \text { and Z [...] Even now that we have eliminated MenA, we still } \\
\text { have Meningitis cases" (Int \#7) }\end{array}$ & $\begin{array}{l}\text { Cold-chain independent vaccine (1) } \\
\text { "It was a vaccine that was able to be provided outside of the } \\
\text { cold-chain, which was critical in terms of getting it out to people } \\
\text { who needed it in remote areas" (Int \#16) }\end{array}$ \\
\hline \multicolumn{2}{|c|}{ CFIR Domain and Construct: Cost (Intervention Characteristics) } \\
\hline Barriers & Facilitators \\
\hline \multicolumn{2}{|l|}{$\begin{array}{l}\text { Delay in EPI uptake due to lack of funding from the Gates } \\
\text { Foundation and GAVI (1) } \\
\text { "Some of the issues is that near the end we ran out of additional grants } \\
\text { from the Gates Foundation and therefore became much more defeated } \\
\text { to find money and by that time the Gates Foundation had grown and } \\
\text { were not willing to give us money without strings attached. So we had a } \\
\text { hard time, we struggled to get the money for the completion pediatric } \\
\text { program. We had difficulties also with Gavi" (Int \#14) }\end{array}$} \\
\hline \multicolumn{2}{|c|}{ CFIR Domain and Construct: External Policy and Incentives (Outer Setting) } \\
\hline Barriers & Facilitators \\
\hline Increasing control of funds from Gates Foundation (1) & Funding flexibility and autonomy early in project (1) \\
\hline
\end{tabular}


"[...] adapting to the changing environment and approach of the Gates Foundation as the project grew and also became more complex, was a challenge, definitely, was a challenge" (Int \#16)
"The Gates Foundation, which was its beginning at that time because they didn't have human capacity at the foundation, decided to give us money in one go. So from the beginning the money was available. There was no chance from the donor to micromanage, to try to influence, to whatever. The money was out" (Int \#14)

De-recognition of Indian regulators (2)

"Unfortunately, I think there was a situation in India at that time in 2007 or 2008, when the national control authority was de-recognised by the WHO, and that was one of the major setbacks" (Int \#1)

Delay in individual country licensing/vaccine registration (1)

"We brought the countries together to do their reviews of these assessment reports with the support of WHO prequalification, and it came to going back now to the countries for each individual country to license the vaccine or register its use to be in their campaigns which were used to introduce the vaccine. Of course, some of the countries took a while to do this" (Int \#13)

CFIR Domain and Construct: Structural Characteristics (Inner Setting)

\begin{tabular}{|c|c|}
\hline Barriers & Facilitators \\
\hline & $\begin{array}{l}\text { WHO's respected reputation (1) } \\
\text { "The African Regional Offices and Country Offices for WHO are } \\
\text { highly respected and have a lot of authority in those areas. So } \\
\text { working closely with them and being based in Geneva and } \\
\text { having them as a partner was critical" (Int \#16) }\end{array}$ \\
\hline \multicolumn{2}{|c|}{ CFIR Domain and Construct: Tension for Change (Inner Setting) } \\
\hline Barriers & Facilitators \\
\hline $\begin{array}{l}\text { Unwillingness of neighbouring governments (low-risk countries) } \\
\text { to adopt the vaccine (1) } \\
\text { I was to eliminate, so to also vaccinate all the surrounding countries of } \\
\text { all the risk countries. For example, Uganda is a high-risk country for } \\
\text { meningitis, so Tanzania was supposed to also be vaccinated. } \\
\text { [...] They say that the risk is low" (Int \#3) }\end{array}$ & $\begin{array}{l}\text { Commitment and advocacy of African leaders ( } 8 \text { ) } \\
\text { "The partnership with the leaders of the African countries who } \\
\text { made a commitment, a verbal commitment to see this forward } \\
\text { because of the magnitude and threat this had for their nations } \\
\text { and their peoples" (Int \#2) }\end{array}$ \\
\hline
\end{tabular}

\section{Delays in routine vaccine introduction (1)}

"[...] So we really there was a lot of momentum to get that vaccine out there in the form of a mass preventive campaign but the problem was that now that we see that decoupling, we have countries that even though the WHO recommendation is to introduce in their routine the maximum five years after they've done the mass preventive campaign, we're seeing countries that are delaying the introduction for much longer than that" (Int \#9)

CFIR Domain and Construct: Compatibility (Inner Setting)

\begin{tabular}{|c|c|}
\hline \multicolumn{2}{|c|}{ CFIR Domain and Construct: Compatibility (Inner Setting) } \\
\hline Barriers & Facilitators \\
\hline $\begin{array}{l}\text { Competing ideas between MVP stakeholders ( } 2 \text { ) } \\
\text { "We were very different partners - PATH and WHO - so we had our } \\
\text { agreement and disagreement" (Int \#14) }\end{array}$ & $\begin{array}{l}\text { Willingness of manufacturer (Serum Institute of India) to } \\
\text { develop cost-effective vaccine (1) } \\
\text { "I would also say that Serum Institute is a very good partners } \\
\text { because they accepted to develop at this low cost. So this } \\
\text { vaccine is a cost effectiveness vaccine" (Int \#16) }\end{array}$ \\
\hline \multicolumn{2}{|c|}{ CFIR Domain and Construct: Leadership Engagement (Inner Setting) } \\
\hline \multirow[t]{2}{*}{ Barriers } & Facilitators \\
\hline & $\begin{array}{l}\text { Regular involvement of recipient countries and } \\
\text { stakeholders in planning/development process (1) } \\
\text { "[...] the discussion was open, and everybody knew the } \\
\text { discussion was going on and knew the final decision and the } \\
\text { rational for that final decision. So, it's a bit of mix of } \\
\text { management, clear, detailed project" (Int \#5) }\end{array}$ \\
\hline \multicolumn{2}{|c|}{ CFIR Domain and Construct: Available Resources (Inner Setting) } \\
\hline Barriers & Facilitators \\
\hline $\begin{array}{l}\text { Inadequate funding by country governments (3) } \\
\text { "Of course there were also challenges in terms of funding, in terms of, } \\
\text { even though most of the operational costs were provided by partners, } \\
\text { Gavi, when it came to getting the government at all levels to participate } \\
\text { or contribute to the funding it was also challenging in some countries" }\end{array}$ & $\begin{array}{l}\text { Country-level (Burkina Faso) training of health workers (1) } \\
\text { "I must say that I think my full compliments to Burkina, because } \\
\text { they were the first ones to introduce country wide, [...] they had } \\
\text { activated the machinery and the health workers, given them } \\
\text { training sufficiently, to ensure that this target is completed, and }\end{array}$ \\
\hline
\end{tabular}




\begin{tabular}{|c|c|}
\hline (Int \#17) & which they did complete" (Int \#1) \\
\hline $\begin{array}{l}\text { Insufficient staff and training ( } 3 \text { ) } \\
\text { "[...] So we could have invested a little bit more in human resources. I } \\
\text { think that would have been a plus. It would have made it easier to } \\
\text { implement because you can't be everywhere" (Int \#8) }\end{array}$ & $\begin{array}{l}\text { Infrastructure support (1) } \\
\text { "Lastly, I would say that the development of infrastructure to } \\
\text { support vaccine introduction, which was part of the program, } \\
\text { was critical" (Int \#16) }\end{array}$ \\
\hline \multicolumn{2}{|l|}{$\begin{array}{l}\text { Logistical gaps in health systems (3) } \\
\text { "The health systems, most of the time, are not very strong enough to } \\
\text { sustain large-scale interventions. So, we have logistical issues. } \\
\text { [...] So it's an issue of logistics and reliance on external support" (Int } \\
\text { \#12) }\end{array}$} \\
\hline \multicolumn{2}{|c|}{ CFIR Domain and Construct: Access to Knowledge and Information (Inner Setting) } \\
\hline Barriers & Facilitators \\
\hline $\begin{array}{l}\text { Insufficient sensitisation at local and national level (1) } \\
\text { "The other thing is insufficient sensitisation. Sometimes the government } \\
\text { does rush, they skip some of the key steps toward the proper } \\
\text { implementation, proper acceptance of the vaccine from the } \\
\text { communities" (Int \#12) }\end{array}$ & $\begin{array}{l}\text { Strong communication strategy including crisis } \\
\text { communication (5) } \\
\text { "But we had developed a crisis communication strategy to deal } \\
\text { with this situation where we said scenario } 1 \text {. If someone dies } \\
\text { during the campaign. Scenario } 2 \text { if, for example, we are working } \\
\text { with meningococcal A vaccine and during our campaign there } \\
\text { are people who have an outbreak or in a country with } \\
\text { meningococcal C or another, serogroup" (Int \#8) }\end{array}$ \\
\hline \multicolumn{2}{|c|}{ CFIR Domain and Construct: Knowledge and Beliefs about the Intervention (Characteristics of Individuals) } \\
\hline Barriers & Facilitators \\
\hline \multicolumn{2}{|l|}{$\begin{array}{l}\text { Complacency of MenA eradication (1) } \\
\text { "[...] there was not a single case of meningitis A in the vaccinated } \\
\text { population. So that gave some sort of a false complacency to the people, } \\
\text { health authorities and the public in general, that now the Meningitis A } \\
\text { is gone" (Int \#1) }\end{array}$} \\
\hline \multicolumn{2}{|l|}{$\begin{array}{l}\text { Vaccine misinformation (3) } \\
\text { "And we often had difficult situations, the most difficult situations. It } \\
\text { was in Mauritania, in Chad, in } 2011 \text { or at one point, we had } \\
\text { newspapers in the media that wrote that there were people who were } \\
\text { paralysed after being vaccinated with MenAfriVac vaccine" (Int \#8) }\end{array}$} \\
\hline \multicolumn{2}{|c|}{ CFIR Domain and Construct: Planning (Process) } \\
\hline \multirow[t]{3}{*}{ Barriers } & Facilitators \\
\hline & $\begin{array}{l}\text { Adequate time for planning project (2) } \\
\text { "We had started working on the introduction framework for the } \\
\text { vaccine three years before the vaccine was ready to be } \\
\text { introduced, so, the lesson being the secret is always planning, } \\
\text { planning, planning, planning, and then planning" (Int \#4) }\end{array}$ \\
\hline & $\begin{array}{l}\text { Well-defined scope of project (2) } \\
\text { "Perhaps one of the reasons for success was this was a very } \\
\text { focused project, we are creating a vaccine against one group of } \\
\text { meningococcus A, which is the main cause of these epidemics" } \\
\text { (Int \#15) }\end{array}$ \\
\hline \multicolumn{2}{|c|}{ CFIR Domain and Construct: Formally Appointed Internal Implementation Leaders (Process) } \\
\hline \multirow[t]{2}{*}{ Barriers } & Facilitators \\
\hline & $\begin{array}{l}\text { Leadership of Project Director (10) } \\
\text { "I would say, is very strong and consistent leadership. } \\
{[\text {.... He is, and certainly was, and is, a remarkable leader. }} \\
\text { [...] he really led that project with a strong focus and a sort of } \\
\text { relentless drive to get it done, and I think that was very, very } \\
\text { helpful to the project" (Int \#16) }\end{array}$ \\
\hline \multicolumn{2}{|c|}{ CFIR Domain and Construct: External Change Agents (Process) } \\
\hline Barriers & Facilitators \\
\hline $\begin{array}{l}\text { Early product cancellation by contracted lab (1) } \\
\text { "I think I can tell you another process which made the job very difficult, } \\
\text { that the lab who was contracted initially by PATH who developed the } \\
\text { conjugate technology in Sienna. } \\
\text { [...] they get a message from this lab that the project is cancelled. And } \\
\text { they whatever technology they had developed, they will not transfer to } \\
\text { MVP." (Int \#1) }\end{array}$ & $\begin{array}{l}\text { Strong technical expertise (3) } \\
\text { "So, I think I would say for the development of the vaccine, the } \\
\text { help of consultants that were highly expert in the field. These } \\
\text { helped enormously" (Int \#18) }\end{array}$ \\
\hline
\end{tabular}




\begin{tabular}{|l|l|}
\hline $\begin{array}{l}\text { Disinterest of Big Pharmaceuticals to partner for MenA vaccine } \\
\text { (3) } \\
\text { "The barriers I think has been relatively difficult to identify among a } \\
\text { manufacturer that would accept to manufacture for that price." (Int \#5) }\end{array}$ & $\begin{array}{l}\text { Involvement of variety of partners/stakeholders (9) } \\
\text { "I think the fact that the project, the MVP, was a very large } \\
\text { consultation of partners, made it to be an opportunity for } \\
\text { partners and governments to come together in a collaborative } \\
\text { way to work together and look at the same voice, same object. } \\
\text { So, this happened and contributed to the success of the project" } \\
\text { (Int \#17) }\end{array}$ \\
\hline \multicolumn{2}{|c|}{ CFIR Domain and Construct: Executing (Process) } \\
\hline \multicolumn{2}{|c|}{ Barriers Facilitators } \\
\hline $\begin{array}{l}\text { Security threats from epidemics and civil war (1) } \\
\text { "You have this one in South Sudan, we were obliged to postpone } \\
\text { because of insecurities, civil war" (Int \#3) }\end{array}$ & $\begin{array}{l}\text { Capacity building integration in national systems (1) } \\
\text { "Developing, testing and introducing the vaccine by giving a lot } \\
\text { of capacity building in the country and we make sure that it was } \\
\text { not a vertical program even when they show when the time of } \\
\text { introducing the vaccine came, he put to develop the project into } \\
\text { the internal structure of WHO as well as the country } \\
\text { organisation. I think all these together make a lot of awareness } \\
\text { and engagement" (Int \#10) }\end{array}$ \\
\hline
\end{tabular}

Note. One sample excerpt is listed for each barrier and facilitator, and the number in brackets following the name of each barrier or facilitator indicates the number of interviewees who cited each barrier and facilitator.

quality and cost of MenAfriVac were barriers mentioned by three stakeholders. Lastly, four key informants listed complexities such as licensing and vaccine registration challenges, slow production of vaccines, and delays in vaccine development in the earlier stages of the project. For example, one interviewee discussed the delays in vaccine development, mentioning " [...] the challenge with, you know, starting off with one kind of technology and they left the project, and we had to find another one." (Interviewee 11). These barriers under the intervention characteristics domain provide insight into the challenges that arose from the production, scaling-up, licensing, and registration of MenAfriVac.

\section{EXTERNAL SETTING}

This domain described changes in the external setting-decisions and changes made outside of the MVP-that can positively or negatively influence implementation.

One stakeholder discussed the early structure of the Gates Foundation and the funding flexibility and autonomy granted to the MVP project, which was key facilitators of the project. As stated by the key informant, "[...] the Gates Foundation had a relatively small staff, and there was a large amount of funding that was provided for this project that really allowed the leaders of the project and the partners of the project to be creative in moving forward. So that was another important, I think, the driver for success." (Interviewee 16)

Four key informants were in consensus regarding the barriers related to the external strategies for spreading the intervention. These included policies and incentives that influenced the implementation of MenAfriVac and the MVP initiative in general. The de-recognition of Indian regulators by the WHO and the increasing control of funds from the BMGF much later in the project were mentioned as key challenges to the effective and timely implementation of MVP goals.

\section{INTERNAL SETTING}

The internal setting domain included characteristics of the implementing organisation and its partners that might in- fluence implementation. For this study, the implementing organisations/partners include the WHO, PATH, and country governments.

Under the internal setting domain, stakeholders mentioned facilitators under three constructs. One key informant discussed the WHO's structural characteristic as facilitating factor as well as the advantages of working and partnering with a large global health organisation. Second, nine key informants mentioned facilitators that fall under implementation climate, including the commitment and advocacy of African leaders and the willingness of the manufacturer to develop cost-effective vaccines. Further, one interviewee discussed how the "[African governments] were completely on board from the start. They were regularly updated because it was a yearly meningitis partners meeting with the country, and there were yearly updates on the development of the project." (Interviewee 5). Lastly, eight key informants discussed the regular involvement of recipient countries and stakeholders in the planning and development process, country-level training of health workers, and strong communication strategies, including crisis communication as facilitators, that led to the success of the MVP initiative.

The MVP initiative involved numerous stakeholders and networks from various countries, organisations, and disciplines. With multiple stakeholders involved, the challenges that four stakeholders mentioned included the unwillingness of neighbouring governments (low-risk countries) to adopt the vaccine, delays in routine vaccine introduction, priority setting from several country governments, and compatibility challenges in balancing several groups and their ideas. One key informant stated, "we were seeing a lot of these countries losing the momentum to actually introduce the vaccine in their routine program." (Interviewee 9). Moreover, eight stakeholders indicated inadequate funding by country governments, unavailable resources (i.e., insufficient staff and training), and lack of access to knowledge and information as challenges to the seamless implementation of MVP goals. 
Table 2. Frequency table of cited Consolidated Framework for Implementation Research (CFIR) constructs (barriers and facilitators) related to the implementation of MenAfriVac through the Meningitis Vaccine Project (MVP) $(\mathbf{n}=18)$

\begin{tabular}{|c|c|c|}
\hline CFIR domains $(n=5)$ and constructs $(n=39)$ & Barrier $\mathrm{n}(\%)$ of interviews & Facilitator $\mathrm{n}(\%)$ of interviews \\
\hline \multicolumn{3}{|l|}{ I. Intervention characteristics } \\
\hline A. Intervention Source & $1(6 \%)$ & None identified \\
\hline B. Evidence Strength and Quality & None identified & None identified \\
\hline C. Relative Advantage & None identified & None identified \\
\hline D. Adaptability & None identified & $1(6 \%)$ \\
\hline E. Trialability & None identified & $2(11 \%)$ \\
\hline F. Complexity & $4(22 \%)$ & None identified \\
\hline G. Design Quality and Packaging & $2(11 \%)$ & $1(6 \%)$ \\
\hline H. Cost & $1(6 \%)$ & None identified \\
\hline \multicolumn{3}{|l|}{ II. Outer Setting } \\
\hline A. Patient Needs and Resources & None identified & None identified \\
\hline B. Cosmopolitanism & None identified & None identified \\
\hline C. Peer Pressure & None identified & None identified \\
\hline D. External Policy and Incentives & $4(22 \%)$ & $1(6 \%)$ \\
\hline \multicolumn{3}{|l|}{ III. Inner Setting } \\
\hline A. Structural Characteristics & None identified & $1(6 \%)$ \\
\hline B. Network and Communications & None identified & None identified \\
\hline C. Culture & None identified & None identified \\
\hline \multicolumn{3}{|l|}{ D. Implementation Climate } \\
\hline 1. Tension for Change & $2(11 \%)$ & $8(50 \%)$ \\
\hline 2. Compatibility & $2(11 \%)$ & $1(6 \%)$ \\
\hline 3. Relative Priority & None identified & None identified \\
\hline 4. Organisational Incentives and Rewards & None identified & None identified \\
\hline 5. Goals and Feedback & None identified & None identified \\
\hline 6. Learning Climate & None identified & None identified \\
\hline \multicolumn{3}{|l|}{ E. Readiness for Implementation } \\
\hline 1. Leadership Engagement & None identified & $1(6 \%)$ \\
\hline 2. Available Resources & $7(39 \%)$ & $2(11 \%)$ \\
\hline 3. Access to Knowledge and Information & $1(6 \%)$ & $5(28 \%)$ \\
\hline \multicolumn{3}{|l|}{ IV. Characteristics of Individuals } \\
\hline A. Knowledge and Beliefs about the Intervention & $4(22 \%)$ & None identified \\
\hline B. Self-Efficacy & None identified & None identified \\
\hline C. Individual Stage of Change & None identified & None identified \\
\hline D. Individual Identification with Organisation & None identified & None identified \\
\hline E. Other Personal Attributes & None identified & None identified \\
\hline \multicolumn{3}{|l|}{ V. Process } \\
\hline A. Planning & None identified & $3(17 \%)$ \\
\hline \multicolumn{3}{|l|}{ B. Engaging } \\
\hline 1. Opinion Leaders & None identified & None identified \\
\hline 2. Formally Appointed Internal Implementation Leaders & None identified & $10(56 \%)$ \\
\hline 3. Champions & None identified & None identified \\
\hline 4. External Change Agents & $4(22 \%)$ & $12(67 \%)$ \\
\hline C. Executing & $1(6 \%)$ & $1(6 \%)$ \\
\hline
\end{tabular}




\begin{tabular}{|c|l|l|}
\hline CFIR domains $(\mathrm{n}=5)$ and constructs $(\mathrm{n}=\mathbf{3 9})$ & Barrier $\mathbf{n}(\%)$ of interviews & Facilitator $\mathbf{n}(\%)$ of interviews \\
\hline D. Reflecting and Evaluating & None identified & None identified \\
\hline
\end{tabular}

\section{CHARACTERISTICS OF INDIVIDUALS}

This domain focused on the actions and behaviours of individuals and their effect through their teams, units, networks, and organisations on implementation.

No facilitators were mentioned under this domain.

Knowledge and beliefs regarding the intervention was the single construct listed under this domain and was mentioned by four key informants as a barrier to the initiative. The complacency related to the eradication of meningitis A and vaccine misinformation were challenges in the uptake of MenAfriVac by authorities and the public in general, respectively. As highlighted by one interviewee, “There was a lot of writing on the web and even in the newspapers saying that Bill Gates was killing children in Africa. [...] So, it was one of the most difficult situations." (Interviewee 8).

\section{PROCESS}

The process domain included the strategies that influenced the implementation at all stages of the project.

Most of the facilitators discussed by stakeholders are found under this domain, including the planning, engagement, and execution processes. Three key informants discussed the constant and organised planning process that was implemented for the MVP initiative. In addition, ten key informants praised the effective and strong leadership of the project director and the strong technical expertise that was sought as crucial facilitators to the initiative's success. Moreover, twelve stakeholders described the important role that external organisations, affiliates, and other supporters played in rendering this initiative successful. Lastly, one key informant highlighted the capacity building prioritised to integrate the MVP initiative into national health systems. Most informants collectively mentioned the planning, engagement, and execution processes as the key facilitator to the success of the MVP initiative. One interviewee shared that "the MVP was a very large consultation of partners, made it to be an opportunity for partners and governments to come together in a collaborative way to work together and look at the same voice, the same object. So, this happened and contributed to the success of the project." (Interviewee 17).

Four stakeholders discussed barriers that occurred at the onset of the project, such as the early product cancellation by a contracted lab and the disinterest of Big Pharmaceuticals to partner with the MVP to create a cost-effective vaccine. Moreover, one stakeholder also described barriers related to the execution process due to security threats (such as war and other epidemics).

\section{DISCUSSION}

Stakeholders involved in the implementation of the MVP are the focus of this study, as they provide valuable in- formation on the processes that have rendered the efforts of the MVP successful. We have revealed multiple facilitators and barriers to a large-scale vaccine project in which numerous stakeholders are involved and display the importance of the preparatory stages before and during implementation. The key informants stated various barriers and facilitators, falling under all five domains of the CFIR framework, including intervention characteristics, external setting, internal setting, characteristics of individuals, and process. The key and most common facilitators to MVP revolved around the inner setting and the process domains of the CFIR.

Our findings complement existing literature as key informants cited critical facilitators that were echoed by previous studies. The cold chain infrastructure of the MenAfriVac was mentioned as a contributing factor to the success of the MVP initiative, as was the case in a previous study analysing the benefits of using vaccines out of the cold chain during the mass immunisation campaign in Benin. ${ }^{19}$ This study emphasised the benefits of MenAfriVac's cold-chain independence for cases in which health centres and target populations are far from each other. In addition, the funding flexibility and autonomy early in the MVP initiative were mentioned as a facilitator to the project's success. One study supports the notion of funding flexibility, as BMGF started to seek new global health projects to invest around the time the MVP was initiated. ${ }^{7}$

Regarding inner setting characteristics, our study revealed both the advocacy of African leaders and the willingness of the Serum Institute of India to develop a cost-effective vaccine as key facilitators were important facilitators to the implementation of the MVP. PATH released a report identifying the advocacy and call for action from African ministries of health to find a solution to the 1996-1997 meningitis A epidemics. ${ }^{20}$ The report described the plea from African leaders and public health officials to create a cost-effective vaccine, leading to the unique partnership with the Serum Institute of India as the MVP's vaccine manufacturer. As stated by most stakeholders, the various partnerships affiliated with the MVP contributed significantly to the implementation across the Meningitis Belt. This sentiment is complimented by one study analysing the multiple stages of MVP governance, development, and partnership accruement. ${ }^{4}$

Given the frequency of results around the inner setting and process CFIR domains, we find that organisational theories best capture the goal of upstream sustainability and the scope of participant responses. Since 2009, increased attention has been paid to the organisational theory for implementation-the ORC theory. ${ }^{9}$ Our results map well to three core aspects of this theory: change valence, task assessment, change efficacy, and drivers of organisational readiness. First, change valence in ORC describes motivational theory-based group value of an impending change. ${ }^{9}$ 
It illustrates that an organisation's readiness will align with its interests and perceived organisational value, down to the individual. Climate and readiness in the MVP were frequently reported across barriers and facilitators alike, indicating a spectrum of change valence across recipient countries. Indeed, in 2009, Weiner first postulated that organisational readiness might be related in scope to Klein and Sorra's (1996) construct of implementation climate. Therefore, this maps well to Weiner's views on change valence. ${ }^{21}$

Second, change efficacy in ORC draws on social theories to identify three aspects of a task-its demands, resources, and situational factors-that comprise an organisation's assessment of its adoption. ${ }^{9}$ This is in line with our findings that complexity, resource unavailability, and a range of country-specific situational factors were associated with poorer readiness and low change-associated effort in specific country cases. ${ }^{21}$

Finally, our results align with what ORC identifies as positive influences on an organisation's readiness: leadership, consistent messaging, and a shared sense of project value. Organisational readiness posits that consistent leadership, information sharing, messaging, and social interaction-or engagement in this context-promote a shared sense of readiness that contributes to a shared experience and more significant change investments. ${ }^{9}$ Similarly, in this study, we identified leadership, multiple levels of engagement, and access to information as critical facilitators. One key informant spoke in favour of the project director's leadership, stating that "[...] he really led that project with a strong focus and a sort of relentless drive to get it done, and I think that was very, very helpful to the project." (Interviewee 16). Overall, we observed that leadership, engagement, and consistency in advocacy and information sharing upstream do facilitate success, whereas poor readiness and climate or complexity implied challenges. Given our results being similar to the ORC, we suggest further investigation and mapping of engagement and readiness/climate constructs as they relate to the theory for great accuracy. A novel retrospective follow-up on the MVP initiative could examine our exploratory themes and constructs regarding stakeholder or decision-maker contexts, policies, and actions that (i) have practical implications to organisational readiness, (ii) promote positive task assessment according to the ORC, and (iii) are associated with greater engagement.

Practically, organisational readiness may be further driven through open information sharing and further community engagement. Given existing strong implementation leadership, engagement may benefit from diversifying its source. This can be achieved through investing in communication campaigns, specifically involving communities as external change agents to their own implementation and involving community-based implementation champions and opinion leaders in rollouts. These benefit from additional community resource mobilisation and intervention ownership, thereby further increasing the probability of embeddedness. Importantly, follow-ups to the MVP and additional vaccine rollouts can leverage a strong sense of project value and engage actors toward greater readiness for change through consistently strong leadership, open information-sharing and messaging, and partnership building.

\section{IMPLICATIONS FOR IMPLEMENTATION PRACTITIONERS}

The view of the implementation landscape revealed in this analysis advances knowledge regarding how to maximise the implementation of vaccination programs in Africa in ways that can immediately inform ongoing program delivery and the design of future vaccination programs. First, there was a strong tension for change-the degree to which stakeholders perceive the current situation as intolerable or requiring change. The palpable tension was translated into the commitment and advocacy of African leaders to bring attention and urgency to address the burden of meningitis A. Second, formally appointed internal implementation leaders were critical in successful vaccine implementation. The project director of the MVP provided excellent leadership and expertise, thereby rendering the initiative successful. The technical expertise sought and provided throughout the implementation stages was a critical facilitator to successfully implementing the vaccine program. This was achieved through the engagement of product experts, the EPI immunisation department of the WHO, and epidemiologists. Third, external change agents were vital. The involvement of multiple partners and stakeholders-such as donors, agencies, government, and communities-was highlighted as a critical facilitator to the success of the MVP. These agents formally influenced and facilitated the intervention decisions in a desirable direction. Finally, key attributes of the vaccine were critical for successful implementation, including stability of the freeze-dried vaccine and its adaptability through the FDA-approved technology transfer to the Serum Institute of India. These, among others, were crucial facilitators of successful development, production, and implementation of the vaccine program.

\section{LIMITATIONS}

This study presents several limitations that must be taken into consideration when interpreting the results. A potential limitation was our selection of a determinant framework (CFIR), as such frameworks have been criticised for their inadequacy in addressing how change takes place. ${ }^{22}$ Nevertheless, the framework served as a valuable tool for organising and contextually understanding data. ${ }^{23}$ Further, the CFIR assisted in triangulating information, allowed us to conceptualise the barriers and facilitators in a more organised manner, resulted in the identification of 16 out of 39 CFIR constructs, and allowed the findings to be placed in the context of the wider implementation research literature. ${ }^{24,25}$

In addition, our interviewee pool was limited by the number of key implementation stakeholders that we discovered through our initial literature review, referrals, and snowball sampling. Although our initial list of potential stakeholders to be interviewed was high, only twenty-one met the eligibility criteria established. The outcome of this small sample size may be the inability to determine if our study has considered all factors that would have impacted the scaling of the project. Despite this, our sample size included stakeholders who took on various roles, including 
technical, regulatory, governance, capacity building, deployment, communication, and charitable contributions. This variety of stakeholders proved to be critical in providing many essential perspectives in the upstream implementation of the MenAfriVac across the Meningitis Belt.

Finally, the decision to narrow the study sample to only partners and implementers of the MVP program means that the experiences and perspectives of citizens and healthcare workers administering the MenAfriVac were excluded. We acknowledge that this may serve as a limitation to our study, as these perspectives may have informed the downstream barriers and facilitators of the MVP initiative. However, two recent studies have examined the downstream perspectives of the MVP. The first study highlights the challenges expressed by healthcare workers in implementing the MenAfriVac in the routine childhood immunisation schedule in Burkina Faso. ${ }^{13}$ In the second study, perspectives were the focal point in determining the perspectives of Meningitis A in Ghana. ${ }^{14}$ The niche of the research purpose of our research was focused on organisations, governments, and key individuals involved in upstream processes, compared to existing studies that focused on citizens' and healthcare workers' perspectives. Therefore, our study fills a gap in the existing literature by investigating stakeholders' perspectives around the upstream processes of the MVP initiative.

\section{CONCLUSIONS}

To bridge gaps upstream in understanding the delivery and outcomes of the global MVP, we conducted 18 in-depth, semi-structured interviews with stakeholders involved in the project. All five domains from the CFIR framework were critical in implementing the MVP, including intervention characteristics, the outer and inner settings, the characteristics of individuals, and the process. However, two of these domains (inner setting and process) were most representative as facilitators for MPV. Specifically, the tension for change-the degree to which stakeholders perceive the current situation as intolerable or needing change- advocated by African leaders served as a crucial foundation for solid leadership for the MPV. The leadership came in the form of the project director and other formally appointed leaders, who could plan, engage and execute the project's goals ef- fectively. This leadership translated into consistent messaging, information sharing, and multiple levels of engagement with external change agents (including technical experts), which promoted a shared sense of readiness contributing to significant change investments in implementing MVP.

\section{ACKNOWLEDGEMENTS}

The authors are grateful to Shaathana Ratnasingam for supporting the transcription of interview audio files.

\section{FUNDING}

No funding was received for this research project.

\section{AUTHORSHIP CONTRIBUTIONS}

Study conception and design: OE. Data Collection: MM. Analysis and interpretation of data: MM, TL, and OE. Draft of the manuscript: MM, TL, and OE. Critical revision of the manuscript for important intellectual content: OE, TL and MM. All authors read and approved the final manuscript.

\section{COMPETING INTERESTS}

The authors completed the Unified Competing Interest form at http://www.icmje.org/disclosure-of-interest/ (available upon request from the corresponding author) and declare no conflicts of interest.

\section{CORRESPONDENCE TO:}

\section{Obidimma Ezezika}

Department of Health and Society, University of Toronto, Scarborough, 1265 Military Trail, Toronto, Ontario, M1C 1A4, Canada. obidimma.ezezika@utoronto.ca

Submitted: August 29, 2021 GMT, Accepted: September 18, 2021 GMT 


\section{REFERENCES}

1. Diallo AO, Soeters HM, Yameogo I, et al. Bacterial meningitis epidemiology and return of Neisseria meningitidis serogroup A cases in Burkina Faso in the five years following MenAfriVac mass vaccination campaign. Hozbor DF, ed. PLoS ONE. 2017;12(11):e0187466. doi:10.1371/journal.pone.018 $\underline{7466}$

2. LaForce FM, Okwo-Bele JM. Eliminating epidemic group a meningococcal meningitis in Africa through a new vaccine. Health Affairs. 2011;30(6):1049-1057. do i:10.1377/hlthaff.2011.0328

3. WHO $\mid 100$ millionth person receives lifesaving meningitis vaccine. WHO. Accessed August 20, 2021. https://apps.who.int/mediacentre/news/releases/201 2/meningitis 20121203/en/index.html

4. Tiffay K, Jodar L, Kieny MP, Socquet M, LaForce FM. The evolution of the meningitis vaccine project. Clinical Infectious Diseases.

2015;61(suppl_5):S396-S403. doi:10.1093/cid/civ594

5. Bwaka A, Bita A, Lingani C, et al. Status of the rollout of the meningococcal serogroup a conjugate vaccine in african meningitis belt countries in 2018 . The Journal of Infectious Diseases.

2019;220(Supplement_4):S140-S147. doi:10.1093/infd is/jiz336

6. Djingarey MH, Diomandé FVK, Barry R, et al. Introduction and rollout of a new group a meningococcal conjugate vaccine (Psa-tt) in african meningitis belt countries, 2010-2014. Clinical Infectious Diseases. 2015;61(suppl_5):S434-S441. do $\mathrm{i}: 10.1093 / \mathrm{cid} / \operatorname{civ} 551$

7. Aguado MT, Jodar L, Granoff D, Rabinovich R, Ceccarini C, Perkin GW. From epidemic meningitis vaccines for africa to the meningitis vaccine project. Clinical Infectious Diseases.

2015;61(suppl 5):S391-S395. doi:10.1093/cid/civ593

8. Williams DR, Costa MV, Odunlami AO, Mohammed SA. Moving upstream: How interventions that address the social determinants of health can improve health and reduce disparities. Journal of Public Health Management and Practice. 2008;14(6):S8-S17. doi:10.1097/01.phh.0000338382.3 $\underline{6695.42}$

9. Weiner BJ. A theory of organizational readiness for change. Implementation Sci. 2009;4(1). doi:10.1186/17 48-5908-4-67
10. Ridde V. Need for more and better implementation science in global health. BMJ Glob Health. 2016;1(2):e000115. doi:10.1136/bmigh-201 $\underline{\text { 6-000115 }}$

11. Omoleke SA, Alabi O, Shuaib F, et al. Environmental, economic and socio-cultural risk factors of recurrent seasonal epidemics of cerebrospinal meningitis in Kebbi state, northwestern Nigeria: A qualitative approach. BMC Public Health. 2018;18(S4):1318. doi:10.1186/s12889-018-6196-9

12. Zoma RL, Walldorf JA, Tarbangdo F, et al. Evaluation of the impact of meningococcal serogroup a conjugate vaccine introduction on second-year-oflife vaccination coverage in burkina faso. The Journal of Infectious Diseases.

2019;220(Supplement_4):S233-S243. doi:10.1093/infd is/iiz304

13. Nkwenkeu SF, Jalloh MF, Walldorf JA, et al. Health workers' perceptions and challenges in implementing meningococcal serogroup a conjugate vaccine in the routine childhood immunization schedule in Burkina Faso. BMC Public Health. 2020;20(1):254. doi:10.1186/ s12889-020-8347-z

14. Codjoe S, Nabie V. Climate change and cerebrospinal meningitis in the ghanaian meningitis belt. IJERPH. 2014;11(7):6923-6939. doi:10.3390/ijerp $\underline{\text { h110706923 }}$

15. Damschroder LJ, Aron DC, Keith RE, Kirsh SR, Alexander JA, Lowery JC. Fostering implementation of health services research findings into practice: A consolidated framework for advancing implementation science. Implementation Sci. 2009;4(1):50. doi:10.1186/1748-5908-4-50

16. Qiao S, Da W, Li X, Zhou Y, Shen Z. Occupational stress, burnout, and organizational readiness for change: A longitudinal study among HIV HCPs in China. Psychology, Health \& Medicine. 2021;2021:1-12. doi:10.1080/13548506.2021.1903059

17. Automated transcription to analyse your data nvivo. Accessed August 20, 2021. https://www.qsrinte rnational.com/nvivo-qualitative-data-analysis-softwa re/about/nvivo/modules/transcription

18. Keith RE, Crosson JC, O'Malley AS, Cromp D, Taylor EF. Using the Consolidated Framework for Implementation Research (Cfir) to produce actionable findings: A rapid-cycle evaluation approach to improving implementation. Implementation Sci. 2017;12(1). doi:10.1186/s13012-017-0550-7 
19. Zipursky S, Djingarey MH, Lodjo JC, Olodo L, Tiendrebeogo S, Ronveaux O. Benefits of using vaccines out of the cold chain: Delivering Meningitis A vaccine in a controlled temperature chain during the mass immunization campaign in Benin. Vaccine. 2014;32(13):1431-1435. doi:10.1016/j.vaccine.2014.0 1.038

20. The meningitis vaccine project: A groundbreaking partnership. Accessed September 17, 2021. https://ww w.path.org/articles/about-meningitis-vaccine-projec t/

21. Damschroder LJ, Lowery JC. Evaluation of a largescale weight management program using the consolidated framework for implementation research (CFIR). Implementation Sci. 2013;8(1). doi:10.1186/17 48-5908-8-51

22. Nilsen P. Making sense of implementation theories, models and frameworks. Implementation Sci. 2015;10(1):53. doi:10.1186/s13012-015-0242-0
23. Weir NM, Newham R, Dunlop E, Bennie M. Factors influencing national implementation of innovations within community pharmacy: A systematic review applying the Consolidated Framework for Implementation Research. Implementation Sci. 2019;14(1):21. doi:10.1186/s13012-019-0867-5

24. Means AR, Kemp CG, Gwayi-Chore MC, et al. Evaluating and optimizing the consolidated framework for implementation research (CFIR) for use in low- and middle-income countries: A systematic review. Implementation Sci. 2020;15(1):17. doi:10.1186/s13012-020-0977-0

25. Kirk MA, Kelley C, Yankey N, Birken SA, Abadie B, Damschroder L. A systematic review of the use of the consolidated framework for implementation research. Implementation Sci. 2015;11(1):72. doi:10.1186/s1301 2-016-0437-z 